\title{
CORTISONE AND ITS ANALOGUES IN THE TREATMENT OF THE PARARHEUMATIC DISORDERS
}

\author{
By F. Dudley HaRT, M.D., F.R.C.P. \\ Westminster Hospital, London, S.W.I
}

By the term 'pararheumatic' is meant those diseases frequently called the ' collagen' disorders in current medical literature: polyarteritis nodosa, systemic lupus erythematosus, progressive systemic sclerosis (scleroderma) and dermatomyositis. Cranial arteritis is also included, as the author finds it hard in many cases to differentiate this condition from polyarteritis nodosa. In this group of disorders steroid therapy has been widely used since it first became available and when supplies were restricted in the early days of their clinical assessment two of these conditions-polyarteritis and systemic lupus erythematosus-were with adrenal deficiency states given priority, for both are potentially lethal disorders, the painful and distressing symptoms of which are controlled by steroid therapy more satisfactorily than by any other form of treatment. In these two conditions steroid therapy is the most likely form of treatment to relieve symptoms adequately and there is suggestive evidence that it may significantly prolong life. Although previously considered rare disorders, these conditions are now apparently more common; certainly the diagnoses are being more commonly made now that the medical profession has become increasingly aware of their existence. The danger lies not so much in over-treatment in these two conditions as in late diagnosis and undertreatment, steroid therapy being applied too little and too late.

\section{Polyarteritis Nodosa}

Polyarteritis is a disease with many and varied clinical manifestations, caused essentially by scattered and widespread inflammatory changes in the walls of small arteries and arterioles, veins and capillaries being less affected. Symptoms may, therefore, be referable to many systems and different parts of the body, but fever and arthralgia are the commonest manifestations, true arthritis being more rare. Eosinophilia is present variably and not in all cases; pleurisy, asthma and in- testinal upsets may occur. The kidney may be involved; hypertension and retinopathy are not uncommon. Because of difficulties in the diagnosis of a disease with so many and varied manifestations the Medical Research Council in a recent survey (1957) insisted on histological proof by biopsy and defined the pathological features necessary for diagnosis.

\section{Treatment}

On cortisone or one of its analogues, fever abates, symptoms are relieved and signs may, if dosage is adequate, disappear. The following case history is instructive:

Mr. X was a healthy man until in 1950, at the age of $3 \mathrm{I}$, he began to suffer from ' asthma.' This came and went, but never disappeared completely, and he was admitted for hospital investigation and treatment with negative results. At this time it does not seem that polyarteritis nodosa was suspected. In $195^{2}$ he began to experience lower abdominal pain with passage of blood and mucus in his stool, and a mass was discovered in the right iliac fossa. He was admitted to hospital, where an eosinophilia, fever and nodules along the line of the temporal vessels led to his transfer to the care of Dr. W. E. Lloyd at Westminster Hospital and the diagnosis of polyarteritis nodosa was here confirmed. Biopsy of a temporal artery gave a histological picture in some sections more suggestive of cranial arteritis than polyarteritis nodosa. On corticotrophin, 100 mg. daily by intramuscular injection, his colonic symptoms and palpable mass rapidly abated, eosinophils disappeared from his peripheral blood, nodules faded from his scalp and fever and bronchial spasm disappeared within a few days. On changing to cortisone, symptoms and signs recurred in all sites when dosage was reduced below $62.5 \mathrm{mg}$. daily; at or above this dose all remained well. He remains well now in his fifth year of steroid therapy, satisfactorily balanced on $50 \mathrm{mg}$. cortisone daily. Reduction below this 
dosage is followed within 48 hours by a return of mild bronchial spasm, which is readily controlled by simple antispasmodics. He has remained at work symptom free ever since then and has to date a normal blood pressure and normal renal function.

Such cases are not uncommon. It is the author's experience that, in the main, results are as good as any obtained with steroid therapy in the treatment of inflammatory disorders. The initial dosage may have to be stepped up above the 'safe' level of $75 \mathrm{mg}$. cortisone or $15 \mathrm{mg}$. prednisone or prednisolone daily to effect initial control, for in a dangerously ill febrile subject the correct dose is the dose which works. Subsequently the dosage is reduced to the lowest level which keeps the patient free from major and distressing symptoms. Fatalities may, nevertheless, occur and renal involvement and increasing hypertension may appear in spite of apparently adequate therapy. Production or aggravation of a peptic ulcer are almost as much of a problem in the steroid treatment of these collagen disorders as of rheumatoid arthritis. While remissions may occasionally occur which allow the stopping of therapy, this is the exception rather than the rule, the more common course being continuous day-to-day therapy. Absolute proof that results are better with steroid therapy than without is still lacking. In the Medical Research Council trial (1957) it was not felt possible to have a control group untreated by steroid running in a parallel series and their 17 cases treated continuously for one year were compared with a retrospective control series of 19 cases. The results illustrated the fallacy of such retrospective controls, for at the time of diagnosis the incidence of hypertension, which materially affects the prognosis, was different in the two groups, and differences in survival rate in the two groups may not have reflected the effects of therapy correctly. They comment: 'Cortisone treatment usually produces quick relief of symptoms and suppression of signs. To secure sustained suppression of outward manifestations may require large doses producing troublesome side-effects.' Nevertheless, in many cases such high dosage may be necessary and should be given, even though side-effects may give trouble, for polyarteritis is a serious disease carrying a grave prognosis and productive of many distressing symptoms which can be relieved better by steroid therapy than by any other form of treatment.

One further aspect of steroid therapy should be mentioned. Some cases of rheumatoid arthritis, and of other disorders, develop, usually late in the course of the disease, signs and symptoms of polyarteritis nodosa (Ball, 1954). This disorder may occur in and complicate classical cases of rheumatoid disease in their later stages and this fact has been generally appreciated for some years. Since steroids have become more widely used in the treatment of rheumatoid arthritis such cases have been on the increase (Kemper et al., 1957) and there is a widely held impression that not only may such treatment be in some unknown way responsible for the increasing incidence of polyarteritis, but that once it has occurred steroid therapy in increasing doses is of no avail in adequately suppressing the features of that polyarteritis. Signs of polyarteritis nodosa have not infrequently become apparent on reduction or sudden stopping of dosage (Slocumb, 1953). It is apparent, therefore that though steroid therapy is of great benefit in the treatment of polyarteritis nodosa it may occasionally, paradoxically, appear to contribute to its causation in other disorders. The abrupt onset of polyarteritis nodosa on reduction or cessation of steroid therapy in other conditions has been seen too frequently to be due to chance. It may be that the sudden withdrawal of the anti-inflammatory effect of cortisone on a simple rheumatoid arteritis may precipitate the more florid necrotizing picture of a polyarteritis nodosa.

\section{Cranial Arteritis}

It has seemed to the author for some years past that this disorder should be considered a subgroup or variant of polyarteritis nodosa rather than as a separate disease process. The cranial arteries, external and internal, may be affected in classical polyarteritis nodosa and some sections, as in the case quoted above, may be histologically identical with those seen in cranial arteritis. At autopsy it is common in cases of cranial arteritis to find widespread arterial lesions in trunk and extremities, and clinically there are often widespread manifestations. Cranial arteritis, therefore, seems to some of us to be a variant of polyarteritis more common over the age of 60 years and more common in, but not confined to, the temporal and other cranial arteries rather than a separate disorder. In some instances low-grade aches and pains with a persistently raised erythrocyte sedimentation rate may persist for some months after the acute symptoms have abated; this strongly suggests a persistence of active arteritis elsewhere in the body. Small daily doses of prednisone, prednisolone, hydrocortisone or cortisone control these symptoms adequately, dosage being gradually reduced and discontinued weeks or months later when symptoms appear to have spontaneously subsided. The prostrating temporal headache common in this condition, and the local temporal tenderness, is adequately relieved by steroid therapy as are other painful symptoms, but blind- 
ness may not be prevented. This, the major hazard in cranial arteritis, may in some cases occur relentlessly in spite of apparently adequate dosage.

\section{Systemic (Disseminated) Lupus Erythematosus}

This disorder, though recognized for many years, appears to be on the increase. Since Hargraves and his colleagues described the typical 'L.E.' cell in 1948 systemic lupus erythematosus is being diagnosed with increasing frequency. It must be emphasized that to find the cell is not necessarily to make the diagnosis, for many workers have reported finding typical L.E. cells in apparently straightforward cases of rheumatoid arthritis. The diagnosis remains essentially a clinical one based on the history and physical signs and confirmed by finding typical L.E. cells in more than one specimen of blood. Systemic lupus erythematosus carries a poorer prognosis than does rheumatoid arthritis, and it is important on this score alone to avoid confusion between the two conditions.

Some cases of systemic (disseminated) lupus are mild, some remit for variable periods; in such mild cases graded rest, simple analgesics given as required and avoidance of administration of other drugs unless absolutely essential are all that is necessary. In most cases, however, fever, pain and marked systemic upset call for steroid therapy also, and there is little doubt but that such therapy has not only made life much more pleasant for these sufferers, but has also improved the prognosis and prolonged life (Dubois, 1956). The dose given should be the lowest which relieves the more unpleasant symptoms, for prolonged high dosage therapy (over $75 \mathrm{mg}$. cortisone or $15 \mathrm{mg}$. prednisolone daily) will in time produce some of the well-known hazards of such treatment, gastrointestinal complications and features of Cushing's syndrome, including osteoporosis and fractures of vertebrae or ribs, mental derangement and reduced resistance to infection. In cases where steroid therapy is required, and these will be the majority, prednisone and prednisolone, because of their reduced sodium-retaining and potassium-losing effects, are perhaps the drugs of choice, but hydrocortisone, cortisone or corticotrophin may be preferred in certain individual cases. Under their influence fever abates and the painful inflammatory features of this unpleasant disorder are controlled, but close attention must be paid to every patient requiring large dosage, because of the real danger of inter-current infections or gastrointestinal complications. Sudden major reduction or cessation of the drug may flare up the disease process, occasionally with fatal results.

Before the days of steroid therapy inter-current infections often proved fatal in systemic lupus. Though this may still occur, renal complications are mostly to be feared, for steroid therapy has no effect on them once they are established. Pollak et al. (1957) have given a detailed account of these renal changes and have re-emphasized that, though $h_{-}$ steroid therapy has undoubtedly prolonged life in $\overrightarrow{\bar{s}}$ systemic lupus, it does not prevent the renal lesionso occurring, nor does it affect their progress. The downhill course once this has occurred may ben slow or rapid, varying from a few weeks to somen years. Nitrogen mustard (Dubois, 1956) has been said to improve the renal lesions, but opinions are still divided on this point. Chloroquin therapy, $\vec{\circ}$ advocated in discoid and systemic lupus, remains sub judice as regards the latter disorder; there is no good evidence that it arrests or improves the renal lesion once this has occurred. The interestings lupus-like syndrome occurring in patients treated. for a year or more on hydrazine-ophthalazine $e_{f}^{+}$ aborts spontaneously on withdrawing treatmente without steroid therapy being necessary.

\section{Scleroderma (Progressive Systemic Sclerosis): Dermatomyositis}

These unpleasant disorders are often little $\vec{\complement}$ affected by steroid therapy, though in their earliet stages the patient so treated may notice increasedelasticity of tissues with greater ease and range $\Phi$ movement and an increased sense of well-being: Each case must, therefore, be judged on its meris Hypertension and renal changes may occur in thes face of steroid therapy; indeed, hypertension mayo be aggravated by such therapy. Results are at besto palliative and the natural course of the disease is $\mathbb{D}$ not diverted.

\section{Summary}

Treatment by cortisone or its analogues is today? orthodox therapy in polyarteritis nodosa, systemico lupus erythematosus and cranial arteritis. There is no evidence that it diverts the natural course of these diseases, nor that it prevents renal com plications, but control of unpleasant symptoms makes life more pleasant for the patient, and there is suggestive evidence that life may be prolonged in some cases.

In scleroderma and dermatomyositis, though worthy of trial, treatment with cortisone or onf of its analogues plays a less important part.

Steroid therapy given in other conditions-for example, rheumatoid arthritis-may be followed by the appearance of signs and symptoms of poly? arteritis, particularly if dosage be suddenly drastice ally reduced or stopped. Polyarteritis nodosa (necrotizing polyarteritis), though occasionally occurring in association with rheumatoid arthritis Bibliography continued on page 328 
have, however, given somewhat variable results. The increased circulating blood volume might result in an increased glomerular filtration rate and this has indeed been found to occur during hormone therapy (Metcoff et al., 1951). The increased G.F.R. could conceivably result in the sodium diuresis which is observed to occur. There is much evidence, however, that there is not an essential mechanism, for many patients with untreated ' nephrosis' have been found to have a normal G.F.R. (Bruck et al., 1954) and an increase is not an essential preliminary to a diuresis.

Lange, Graig, Oberman, Slobody, Ogur and IoCasto (195I) and others consider that the nephrotic syndrome results from an antigenantibody reaction involving the glomerular basement membrane. A very similar picture can be produced experimentally with nephrotoxic serum (Masugi, 1933-34) and Lange et al. (195I) find that the serum complement is low during relapse and rises as a remission occurs. In this view ACTH and the glucocorticoids would act by interfering in some way with the antigen-antibody reaction. As yet, however, there has been no substantiated evidence of antibodies to human glomeruli in the plasma of nephrotic patients.

\section{Conclusion}

In suitable patients, who exhibit the nephrotic syndrome, it is always worth while to try the effect of ACTH, cortisone, hydrocortisone, prednisone or prednisolone, provided suitable precautions are taken. A diuresis will frequently be obtained and this at least will make the patient $\vec{Q}$ good deal more comfortable. In addition, how气 ever, a number of patients will become free from all proteinuria and the prognosis in such cases would appear to be quite good.

\section{BIBLIOGRAPHY}

ARNIEL, G. C. (1956), Lancet, i, 409.

BARNES, L. A., MOLL, G. H., and JANEWAY, C. A. (1950) Pediastrics, 5, 486.

BJORNEBOE, M., BRUN, C., GORMSEM, H., IVERSEN, P and RAASCHOU, F. (1952), Acta med scand.' Suppl., 266, 233

BRUCK, E., RAPOPORT, M., and RUBIN, M. I. (1954), f. clini Invest., 33, 699 .

CHARLTON, D., LATNER, A. L., PLATT, J. W., SMART, G. A., THOMPSON, R. B., and WALKER, W. (I957) (In Press).

DEBRE, R., ROYER, P., LEVEQUE, B., and MINOR, Z. (1956) Sem. Hop. Paris, 32, 263.

ELLIS, A. (1942), Lancet, i, I.

FANCONI, G., KOUSMINE, C., FRISCHKNECHT, W. (195 I Helv. paediat. Acta, 6, 219.

FARNSWORTH, E. B. (1950), Clinical ACTH Conference (Ed mote), J. \& A. Churchill Ltd., r950, p. 297.

HAMILTON, M., PICKERING, G. W. FRASER ROBERTS J. A., and SOWRY, G. S. C. (1954), Clin. Sci., 13, I I and 376

JANEWAY, C. A., MOLL, G. H., ARMSTRONG, S. H. Jr N WALLACE, W. M., HALLMẢN, N., and BARNESS, L. ÄW (1948), Trans. Ass. Amer. Phys., 6r, ro8.

KARK, R. M., MUEHRCKE, R. C., PIRANI, C. L., and POLLAK, V. E. (1955), Ann. intern. Med., 43, 807.

KIMMELSTEIL, P., and WILSON, C. (1936), Amer. F. Path. $12,83$.

LANG,E K., GRAIG, F., OBERMAN, J., SLOBODY, L., OGUR G., and IOCASTO, F. (195I), Arch. intern. Med., 88, 433.

LANGE, K., SLOBODY, L., and STRANG, R. (1953), Proc. Soc. exp. Biol. (N.Y.), 82, 315.

LUETSCHER, J. A., Jr., DEMING, Q. B., JOHNSON, B. B., \&n PIEL, C. F. (1953), F. Amer. med. Ass., 153, 1,236.

MASUGI, M. (1933-34), Beitr. path. Anat., 92, 429.

MERRILL, A. J., WILSON, J., and TIMBERLAKE, LCô (1954), Arch. intern. Med., 94, 925.

METCOFF, J, KELSEY, W, RANCE C. P and JANEWAY C. A. (195r), 'Proc. of Second Clinical ACTH Conference (Ed. mote), 2, 148, J. \& A. Churchill Ltd.

SOSHEA, J. W., and FARNSWORTH, E. B. (1951), F. Lab. clin? med., 38, 414

\section{RUTHIN CASTLE, NORTH WALES}

A Clinic for the diagnosis and treatment of Internal Diseases (except Mental or Infectious Diseases). The Clinic is provided with a staff of doctors, technicians and nurses.

The surroundings are beautiful. The climate is mild. There is central heating throughout. The annual rainfall is 30.5 inches, that is less than the average for England.

The Fees are inclusive and vary according to the room occupied.

For particulars apply to THE SECRETARY, Ruthin Castle, North Wales.

Tolegrams: Castle, Ruthin

Telephone: Ruthin 66

Bibliography continued from page 324-F. Dudley Hart, M.D., F.R.C.P. treated conservatively, appears to be more common in steroid treated cases.

\section{BIBLIOGRAPHY}

BALL, J. (i954), Ann. rheum. Dis., 13, 277. DUBOIS, E. L. (1956), Ann. intern. Med., 45, 663.
HARGRAVES, M. M., RICHMOND, H., and MORTON, R. (1948), Proc. Mayo Clin., 23, 25. KEMPER, J. W., BAGGENSTOSS, A. H., and SLOCUMB, C. H (1957), Ann. intern. Med., 46, $83 \mathrm{I}$.

MUEHRCKE, R. C., KARK, R. M., PIRANI, C. L., and POLLAK, V. E. (1957), Medicine, 36, 1 . REPORT OF THE MEDICAL RESEARCH COUNCIL (1957) Brit. med. F., 1,608 .

SLOCUMB, C. H. (x 953), Proc. Mayo Clin., 28, 655. 